\title{
Palladium Nanoparticles in Hypercrosslinked Polystyrene: Synthesis and Application in the Hydrogenation of Arenes
}

\author{
S. E. Lyubimov ${ }^{a, *}$, A. A. Zvinchuk ${ }^{a}$, A. A. Korlyukov ${ }^{a}$, V. A. Davankov ${ }^{a}$, and O. P. Parenago ${ }^{b}$ \\ ${ }^{a}$ A.N. Nesmeyanov Institute of Organoelement Compounds, Russian Academy of Sciences, Moscow, 119991 Russia \\ ${ }^{b}$ A.V. Topchiev Institute of Petrochemical Synthesis, Russian Academy of Sciences, Moscow, 119991 Russia \\ *e-mail:lssp452@mail.ru
}

Received July 7, 2020; revised July 24, 2020; accepted September 18, 2020

\begin{abstract}
A novel method for incorporation of palladium nanoparticles into a porous hypercrosslinked polystyrene matrix has been developed. The composite obtained by reduction of $[\mathrm{Pd}(\pi \text {-allyl }) \mathrm{Cl}]_{2}$ with hydrogen in supercritical $\mathrm{CO}_{2}$ shows high catalytic activity in the hydrogenation of benzene and can be used twelve (12) times in a row without any decrease in conversion rate. The catalyst is also suitable for quantitative hydrogenation of toluene, tetralin and phenol. The obtained catalytic system is compared with the palladium composite synthesized by a conventional method based on hypercrosslinked polystyrene.
\end{abstract}

Keywords: hypercrosslinked polystyrene, palladium nanoparticles, hydrogenation, arenes

DOI: $10.1134 / \mathrm{S} 0965544121010084$

Cyclohexane and its derivatives are important chemical products widely used in organic synthesis (solvents), petroleum chemistry, and pharmaceutical production [1-3]. Cyclohexane derivatives can be obtained either by cyclohexane modification or by hydrogenation of respective substituted aromatic compounds. Due to the low reactivity of cyclohexane, its modification methods are of low efficiency and therefore used comparatively rarely. Thus, catalytic hydrogenation of aromatic derivatives is the main way to obtain substituted derivatives of cyclohexane. Also, of great interest is phenol hydrogenation for obtaining cyclohexanone, which is the basic raw material for the synthesis of adipic acid and caprolactam [4].

Many various metal-complex systems are used as catalysts for benzene-to-cyclohexane hydrogenation; however, the homogeneous catalytic processes, even though they are usually highly active, have some serious drawbacks, the major ones being complexity of separation of the catalyst from reaction products and that it cannot be recycled $[5,6]$. As regards the well-known heterogeneous benzene-to-cyclohexane hydrogenation catalysts, they are represented by the systems based on nickel, platinum, palladium, rhodium, iridium, and ruthenium [7].

In order to increase catalytic activity of heterogeneous catalysts, activity that depends on the size of the metal surface area available for the reacting molecules, it is conventional to use catalysts applied to the porous surface of carriers of an inorganic or polymeric nature. Hypercrosslinked polystyrene (HCP) is one of the promising polymeric supports that is notable for its very high specific surface area (normally ranging from 800 to $1500 \mathrm{~m}^{2} / \mathrm{g}$ ) [8]. For example, nanoparticles of Pt, Pd and Ru incorporated into the HCP matrix have been used for selective oxidation of lactose, glucose, and sorbose [9-12]. Pt and Ru nanoparticles applied to the MN-270 commercial microporous HCP copolymer have been efficiently used for oxidation of phenol dissolved in water [13-14]. Pd nanoparticles immobilized into the MN-270 styrene-divinyl-benzene polymer have been studied in the course of hydrogenation of stearic acid to heptadecane [15]. The catalyst in question has also been tested successfully in the course of phenol gas phase hydrogenation [7]. HCP containing Pd nanoparticles demonstrated high activity in a reaction wherein aryl bromides and chlorides were coupled with phenyl boronic acid [17]. The MN-100 crosslinked copolymer containing $\mathrm{Rh}$ nanoparticles demonstrated high activity in the course of olefin hydroformylation in supercritical $\mathrm{CO}_{2}$ during six catalytic cycles without any loss of conversion rate [18].

In this paper a novel method for obtaining Pd nanoparticles in the HCP matrix is described; the method 
(a)

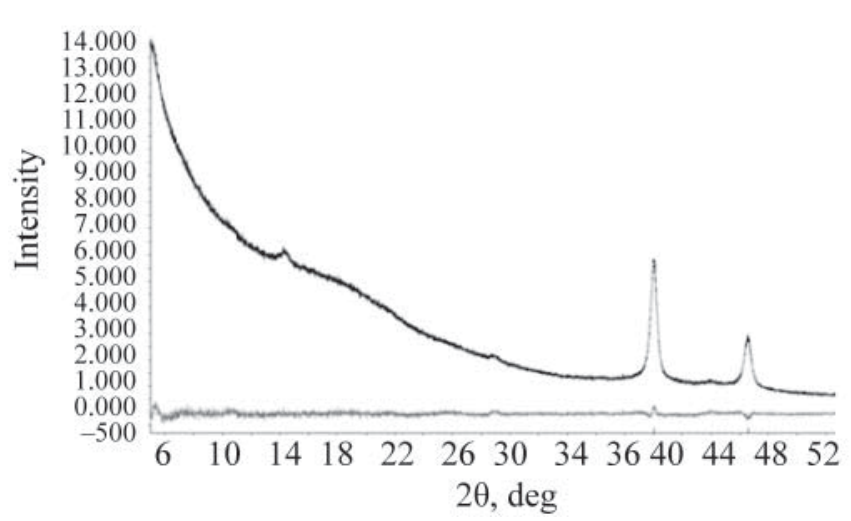

(b)

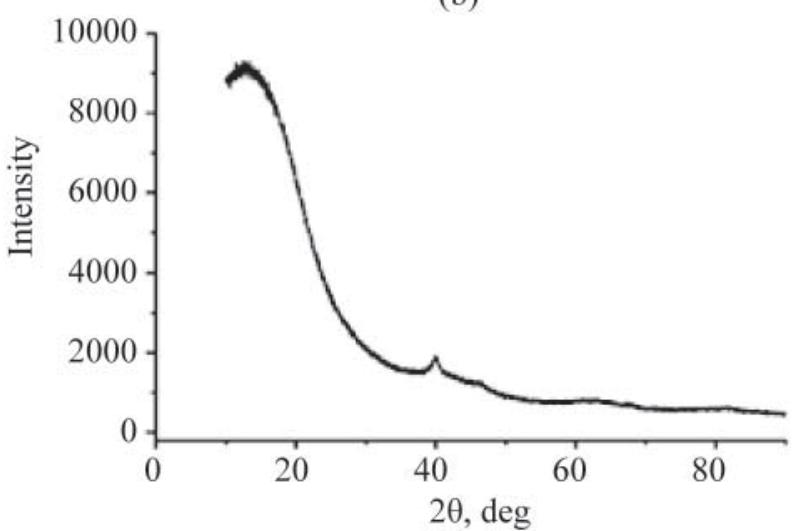

Fig. 1. X-ray powder patterns of composite samples obtained (a) in supercritical $\mathrm{CO}_{2}$, and (b) in aqueous medium.

represents decomposition-reduction of $[\mathrm{Pd}(\pi \text {-allyl }) \mathrm{Cl}]_{2}$ in supercritical $\mathrm{CO}_{2} / \mathrm{H}_{2}$, after which the obtained composite is used in hydrogenation of benzene, toluene, tetralin, and phenol.

\section{EXPERIMENTAL}

Bi-porous hypercrosslinked styrene-divinyl-benzene polymer Macronet MN-200 with the pore sizes being 71 and $1.6 \mathrm{~nm}$ and specific surface area $1100 \mathrm{~m}^{2} / \mathrm{g}$ (Purolite, Great Britain) was used as an adsorbent; it was washed with $\mathrm{MeOH}$ and dried at $110^{\circ} \mathrm{C}$ for $30 \mathrm{~min}$ before use. Bis- $\pi$-allyl palladium chloride (from Sigma-Aldrich) and palladium chloride (from Aurat JSC) were used without any additional treatment.

$[\mathrm{Pd}(\pi \text {-allyl }) \mathrm{Cl}]_{2}, 101 \mathrm{mg}$, were dissolved in $\mathrm{CH}_{2} \mathrm{Cl}_{2}$ $(2.4 \mathrm{~mL})$ and then added to hypercrosslinked polystyrene $(0.7 \mathrm{~g})$; the solvent was removed in vacuum. The reduction of the applied complex to metal was carried out in a stainless steel autoclave, in hydrogen atmosphere (55 atm), and then $\mathrm{CO}_{2}$ was added to increase the total pressure up to $150 \mathrm{~atm}$. The mixture was heated for $3 \mathrm{~h}$ $\left(50^{\circ} \mathrm{C}\right)$, whereafter the pressure was slowly decreased. The obtained grey composite was washed with acetone $(5 \mathrm{~mL})$ and dried in vacuum.

For comparison a palladium catalyst was prepared by a conventional method, wherein $150 \mathrm{mg}$ of $\mathrm{PdCl}_{2}$ were simultaneously being heated and dissolved in $1 \mathrm{~mL}$ of $\mathrm{H}_{2} \mathrm{O}$ and $0.1 \mathrm{~mL}$ of concentrated $\mathrm{HCl}$, and added to $1.0 \mathrm{~g}$ of the Macronet MN-200 adsorbent. The polymer expanded in the above solution for $20 \mathrm{~min}$, and then a solution containing $600 \mathrm{mg}$ of sodium formate and $450 \mathrm{mg}$ of $\mathrm{NaOH}$ in $2 \mathrm{~mL}$ of $\mathrm{H}_{2} \mathrm{O}$ was added thereto. The obtained mixture was heated for $10 \mathrm{~min}$ at $80^{\circ} \mathrm{C}$; the resulting composite product was washed with water
$(30 \mathrm{~mL})$ and $\mathrm{MeOH}(10 \mathrm{~mL})$ and then heat-dried in vacuum $\left(90^{\circ} \mathrm{C}\right)$.

The palladium content in the samples was determined by X-ray fluorescence analysis using an Innov-X $\alpha-2000$ $\mathrm{X}$-ray spectrometer. The morphology of the samples was examined with a Hitachi HT7700 transmission electron microscope. X-ray powder patterns were obtained with a Bruker D8 Advanced diffractometer using $\mathrm{Cu} K_{\alpha}(\lambda=$ $1.5406 \AA$ ) radiation.

Hydrogenation of aromatic compounds was carried out for $24 \mathrm{~h}$ in a stainless steel autoclave at temperatures ranging from 55 to $110^{\circ} \mathrm{C}$, under the required hydrogen pressure, in a substrate medium, which was methylene chloride, or in supercritical $\mathrm{CO}_{2}$. When the reaction was completed, the liquid reaction mixture was separated from the solid catalyst and analyzed by methods such as GLC (Crystall-2000M) and ${ }^{1} \mathrm{H}$ NMR (Bruker 400). Prior to being recycled, the catalyst was dried in vacuum and washed with $\mathrm{CH}_{2} \mathrm{Cl}_{2}$.

\section{RESULTS AND DISCUSSION}

According to the X-ray fluorescence analysis data, the average palladium content in the composites obtained by reduction in supercritical $\mathrm{CO}_{2}$ (sample 1) or with sodium formate in an aqueous medium (see above) (sample 2) was 6.0 and $6.07 \mathrm{wt} \%$, respectively. Figure 1 shows the X-ray powder patterns of both composite samples: on sample 1 (Fig. 1a) we can clearly see the $2 \theta$ diffraction peaks at $39.98^{\circ}$ and $46.56^{\circ}$, and on sample 2 (Fig. 1 b), only at $39.98^{\circ}$; the peaks correspond to the face-centered cubic crystalline structure of Pd nanoparticles. The crystallite size calculation based on the integral breadth of reflections with the use of the Lvol IB formalism shows that the average size of Pd nanoparticles is 14.0 and $8.3 \mathrm{~nm}$ for samples $\mathbf{1}$ and $\mathbf{2}$, respectively. 
(a)

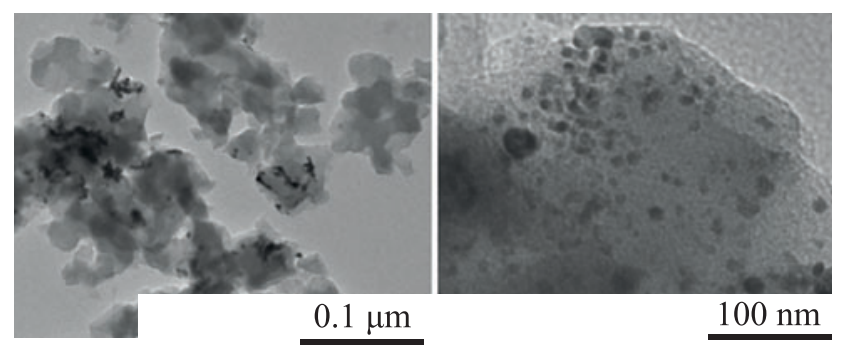

(b)

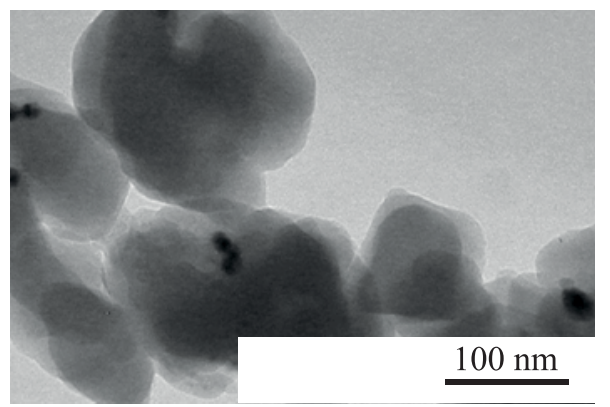

Fig. 2. Composite samples as viewed with the TEM: (a) sample $\mathbf{1}$ obtained in supercritical $\mathrm{CO}_{2}$ and (b) sample 2 obtained in aqueous medium.

Also, the size and morphology of $\mathrm{Pd}(0)$ nanoparticles in the polymer were examined by analyzing the fine composite material with the help of a transmission electron microscope (TEM) (Fig. 2).

Nanoparticles of 5 to $8 \mathrm{~nm}$ were found to have been formed in sample $\mathbf{1}$ along with large palladium clusters. Sample 2 contains palladium particles of virtually the same size $(\sim 10 \mathrm{~nm})$, but these are less densely distributed in the HCP matrix. The histograms showing the distribution of particles in the samples obtained in supercritical $\mathrm{CO}_{2}$ and in water are in Fig. 3.

Palladium composites were used as catalysts for hydrogenation of model aromatic hydrocarbons (Table 1).

(a)

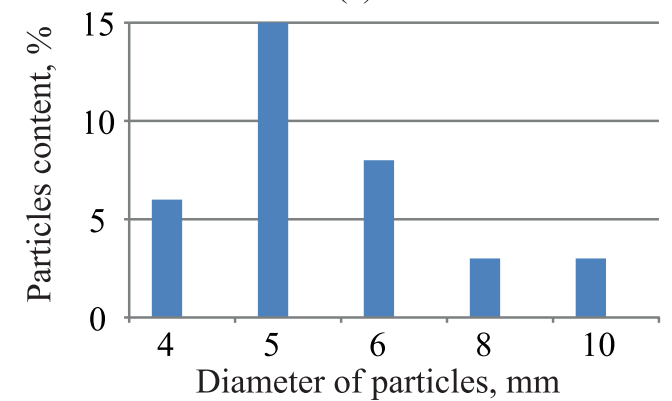

As follows from the data above, benzene conversion at $55^{\circ} \mathrm{C}$ was $55 \%$, and the increase in the reaction temperature to $110^{\circ} \mathrm{C}$ resulted in full conversion of the substrate. As regards the palladium catalyst obtained in aqueous medium, benzene conversion in that case was only $64 \%$ under the same conditions $\left(110^{\circ} \mathrm{C}\right)$.

A series of 12 successive hydrogenation cycles was carried out to check whether the catalyst could be recycled. Full benzene conversion was achieved under the same conditions in all the tests, and after completion of the last cycle no traces of benzene in the reaction mixture were found.

It is also worth noting that during the successive tests, according to the X-ray fluorescence data, palladium particles are not "washed out" of the carrier matrix. Besides benzene, toluene and tetralin were hydrogenated on a catalyst regenerated in the supercritical $\mathrm{CO}_{2}$ medium. They were quantitatively hydrogenated to methylcyclohexane and decalin, respectively (Table 1).

The catalyst was also used for phenol hydrogenation in $\mathrm{CH}_{2} \mathrm{Cl}_{2}$ without solvents, and in supercritical $\mathrm{CO}_{2}$ (Table 2).

In the $\mathrm{CH}_{2} \mathrm{Cl}_{2}$ case, virtually full conversion of phenol is observed, with the cyclohexanol/cyclohexanone ratio being 19/81 (Table 2, test 1); as we can see, selectivity remains nearly the same at a higher hydrogen pressure (Table 2, test 2). Without a solvent, virtually full substrate conversion is achieved as well, but selectivity is lower (Table 2, test 3). When supercritical $\mathrm{CO}_{2}$ is used as the reaction medium, cyclohexanol becomes the main product (Table 2, test 4), and its yield is slightly lower at a higher temperature (Table 2, test 5).

In summary, this paper introduces a novel method of formation of palladium nanoparticles by reduction of $[\mathrm{Pd}(\pi \text {-allyl }) \mathrm{Cl}]_{2}$ with hydrogen in supercritical $\mathrm{CO}_{2}$ in a hypercrosslinked polystyrene matrix. The obtained

(b)

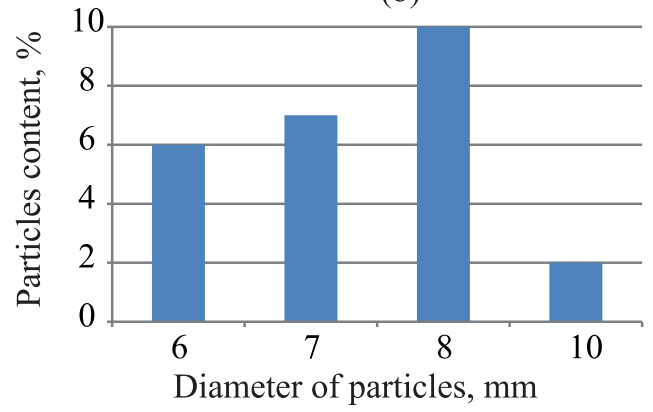

Fig. 3. Histograms of Pd nanoparticles distribution: (a) sample 1 obtained in supercritical $\mathrm{CO}_{2}$; (b) sample 2 obtained in aqueous medium. 
Table 1. Results of hydrogenation of aromatic compounds on Pd composites. [Pd] $=0.5 \mathrm{~mol} \%, P\left(\mathrm{H}_{2}\right)=55 \mathrm{~atm}$, duration $24 \mathrm{~h}$, composite $50 \mathrm{mg}$, arenes $0.45 \mathrm{~g}$

\begin{tabular}{c|l|c|c|l}
\hline Pd composite sample & Substrate & $T,{ }^{\circ} \mathrm{C}$ & Conversion rate, $\%$ & Reaction product \\
\hline $\mathbf{1}$ & Benzene & 55 & 55 & Cyclohexane \\
$\mathbf{1}$ & Benzene & 110 & 100 & Cyclohexane \\
$\mathbf{2}$ & Benzene & 110 & 64 & Cyclohexane \\
$\mathbf{1}$ & Toluene & 110 & 100 & Methylcyclohexane \\
$\mathbf{1}$ & Tetralin & 110 & 100 & Decalin \\
\hline
\end{tabular}

a $\mathbf{1}$ was obtained in supercritical $\mathrm{CO}_{2} ; \mathbf{2}$ was obtained in aqueous medium.

Table 2. Results of phenol hydrogenation on the Pd composite (sample 1). [Pd] $=2.0 \mathrm{~mol} \%, P\left(\mathrm{H}_{2}\right)=55 \mathrm{~atm}$, duration $24 \mathrm{~h}$, composite $33 \mathrm{mg}$, phenol $93 \mathrm{mg}$

\begin{tabular}{c|l|c|c|c|c}
\hline Test no. & \multicolumn{1}{|c|}{ Medium } & Total pressure, atm & $T,{ }^{\circ} \mathrm{C}$ & Conversion rate, $\%$ & Product yield ratio 2: $\mathbf{3}^{\mathrm{a}}$ \\
\hline 1 & $\mathrm{CH}_{2} \mathrm{Cl}_{2}$ & 55 & 55 & 99.7 & $19: 81$ \\
2 & $\mathrm{CH}_{2} \mathrm{Cl}_{2}$ & 150 & 55 & 100.0 & $18: 82$ \\
3 & - & 55 & 55 & 99.5 & $36: 64$ \\
4 & Supercritical $\mathrm{CO}_{2}$ & 150 & 55 & 98.0 & $62: 38$ \\
5 & Supercritical $\mathrm{CO}_{2}$ & 150 & 70 & 100.0 & $55: 45$ \\
\hline
\end{tabular}

${ }^{\text {a }}$ Traces of products 4-6 were found in all the tests. The main phenol hydrogenation reaction products are shown in the diagram below [19-22]:

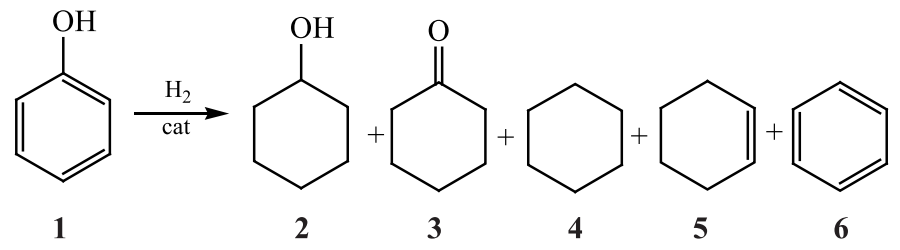

(1) Phenol, (2) cyclohexanol, (3) cyclohexanone, (4) cyclohexane, (5) cyclohexene, (6) benzene.

composite demonstrated high activity during benzene hydrogenation, which did not decline when one and the same catalyst sample was used 12 times. Furthemore, the catalyst proved to be efficient during hydrogenation of toluene to methylcyclohexane and tetralin to decalin, as well as during hydrogenation of phenol to cyclohexanol and cyclohexanone in the $\mathrm{CH}_{2} \mathrm{Cl}_{2}$ medium, in supercritical $\mathrm{CO}_{2}$, and in the substrate.

\section{ADDITIONAL INFORMATION} 7325

S.E. Lyubimov, ORCID: http://orcid.org/0000-0002-7076-

A.A. Zvinchuk, ORCID: http://orcid.org/0000-0001-8257$729 \mathrm{X}$

A.A. Korlyukov, ORCID: http://orcid.org/0000-00025600-9886

V.A. Davankov, ORCID: http://orcid.org/0000-0002-10181840

O.P. Parenago, ORCID: http://orcid.org/0000-0002-48694035

\section{FUNDING}

This work was funded by the Russian Foundation for Basic Research (grant no. 18-29-06032). The authors are grateful to the Department of Structural Studies at N.D. Zelinsky Institute of Organic Chemistry (Moscow) for the electron microscopy analysis.

\section{CONFLICT OF INTEREST}

No conflict of interest was declared by the authors.

\section{OPEN ACCESS}

This article is distributed under the terms of the Creative Commons Attribution 4.0 International License (http:// creativecommons.org/licenses/by/4.0/), which permits unrestricted use, distribution, and reproduction in any medium, provided you give appropriate credit to the original author(s) and the source, provide a link to the Creative Commons license, and indicate if changes were made.

\section{REFERENCES}

1. Stanislaus, A.B. and Cooper, H., Catal. Rev., 1994, vol. 36, p. 75.

https://doi.org/10.1080/01614949408013921

2. Maegawa, T., Akashi, A., Yaguchi, K., Iwasaki, Y., Shigetsura, M., Monguchi, Y., and Sajiki, H., Chem. Eur. J., 2009, vol. 15, p. 6953.

https://doi.org/10.1002/chem.200900361

3. Domanska, U., Morawski, P., and Piekarska, M., J. Chem.

PETROLEUM CHEMISTRY Vol. 61 No. 12021 
Thermodynamics., 2008, vol. 40, p. 710.

https://doi.org/10.1016/j.jct.2007.10.004

4. Nelson, N., Manzano, J., Sadow, A., Overbury, S., and Slowing, I., ACS Catal., 2015, vol. 5, p. 2051. https://doi.org/10.1021/cs502000j

5. Rakowski, M.C., Hirsekorn, F.J., Stuhl, L.S., and Muetterties, E.L., Inorg. Chem., 1976, vol. 15, no. 10, p. 2379.

https://doi.org/10.1021/ic50164a013

6. Bayram, E., Linehan, J.C., Fulton, J.L., Roberts, J.A.S., Szymczak, N.K., Smurthwaite, T.D., Ozkar, S., Balasubramanian, M., and Finke, R.G., J. Am. Chem. Soc., 2011, vol. 133, p. 18889. https://doi.org/10.1021/ja2073438

7. Zhu, L., Sun, H., Fu, H., Zheng, J., Zhang, N., Li, Y., and Chen, B.H., Appl. Catal. A: Gen., 2015, vol. 49, p. 124. https://doi.org/10.1016/j.apcata.2015.04.016

8. Tan, L. and Tan, B., Chem. Soc. Rev., 2017, vol. 46, p. 3322 . https://doi.org/10.1039/c6cs00851h

9. Sidorov, S.N., Volkov, I.V., Davankov, V.A., Tsyurupa, M.P., Valetsky, P.M., Bronstein R. Karlinsey, L.M., Zwanziger, J.W., Matveeva, V.G., Sulman, E.M., Lakina, N.V., Wilder, E.A., and Spontak, R.J., J. Am. Chem. Soc., 2001, vol. 123, no. 43, p. 10502. https://doi.org/10.1021/ja0107834

10. Sulman, E., Matveeva, V., Bronstein, L., Sidorov, A., Lakina, N., Sidorov, S., and Valetsky, P., Green. Chem., 2003, vol. 5, p. 2005. https://doi.org/10.1039/B210350H

11. Sulman, E., Doluda, V., Dzwigaj, S., Marceau, E., Kustov, L., Tkachenko, O., Bykov, A., Matveeva, V., Sulman, M., and Lakina, N., J. Mol. Catal. A: Chem., 2007, vol. 278, p. 112.

https://doi.org/10.1016/j.molcata.2007.08.029

12. Sulman, E.M., Matveeva, V.G., Bronstein, L.M., Sulman, M.G., Doluda, V.D., Tokarev, A.V., Murzina, E.V., and Murzin, D.Yu., Stud. Surf. Sci. Catal., 2006, vol. 162, p. 119. https://doi.org/10.1016/S0167-2991(06)80898-0

13. Doluda, V.Yu., Sulman, E.M., Matveeva, V.G., Sulman, M.G., Lakina, N.V., Sidorov, A.I., Valetsky, P.M., and
Bronstein, L.M., Chem. Eng. J., 2007, vol. 134, p. 256. https://doi.org/10.1016/j.cej.2007.03.069

14. Doluda, V.Yu., Sulman, E.M., Matveeva, V.G., Sulman, M.G., Bykov, A.V., Lakina, N.V., Sidorov, A.I., Valetsky, P.M., and Bronstein, L.M., Top. Catal., 2013, vol. 56, p. 688 . https://doi.org/10.1007/s11244-013-0028-z

15. Sapunov, V.N., Stepacheva, A.A., Sulman, E.M., Warna, J., Maki-Arvela, P., Sulman, M.G., Sidorov, A.I., Stein, B.D., Murzin, D.Yu., and Matveeva, V.G., J. Ind. Eng. Chem., 2017, vol. 46, p. 426. https://doi.org/10.1016/j.jiec.2016.11.013

16. Sulman, E.M., Ivanov, A.A., Chernyavsky, V.S., Sulman, M.G., Bykova, A.I., Sidorov, A.I., Doluda, V.Yu., Matveeva, V.G., Bronstein, L.M., Stein, B.D., and Kharitonov, A.S., Chem. Eng. J., 2011, vols. 176-177, p. 33. https://doi.org/10.1016/j.cej.2011.05.044

17. Lyubimov, S.E., Vasil'ev, A.A., Korlyukov, A.A., Ilyin, M.M., Pisarev, S.A., Matveev, A.E., Chalykh, V.V., Zlotin, S.G., and Davankov, V.A., React. Funct. Polym., 2009, vol. 69, p. 755. https://doi.org/10.1016/j.reactfunctpolym.2009.06.004

18. Lyubimov, S.E., Rastorguev, E.A., Lubentsova, K.I., Korlyukov, A.A., and Davankov, V.A., Tetrahedron Lett., 2013, vol. 54, p. 1116. https://doi.org/10.1016/j.tetlet.2012.12.063

19. Talukdar, A.K., Bhattacharyya, K.G., and Sivasanker, S., Appl. Catal. A: Gen., 1993, vol. 96, p. 229. https://doi.org/10.1016/0926-860X(90)80012-4

20. Chen, H., He, Y., Pfefferle, L.D., Pu, W., Wu, Y., and Qi, S., Chem. Cat. Chem., 2018, vol. 10, p. 2558. https://doi.org/10.1002/cctc.201800211

21. Chatterjee, M., Kawanami, H., Sato, A., Chatterjee, T., and Yokoyama, T., Adv. Synth. Catal., 2009, vol. 351, p. 1912. https://doi.org/10.1002/adsc.200900144

22. Rode, C.V., Joshi, U.D., Sato, O., and Shirai, M., Chem. Commun., 2003, p. 1960.

https://doi.org/10.1039/B304344D 